\title{
Masculinidade e homofobia no futebol: Joguem como homens! (2019), de João Carlos da Cunha Moura
}

\author{
Wagner Xavier Camargo \\ Universidade Federal de São Carlos, São Carlos/Brasil \\ Doutor em Ciências Humanas, UFSC
}

Conheci João Carlos da Cunha Moura em uma mesa sobre "masculinidade tóxica", que ocorreu no Museu do Futebol, em São Paulo, em agosto de 2019, na qual participamos juntos como debatedores. Moura havia recém recebido os exemplares de Jogue como homens! Masculinidades, liberdade de expressão e homofobia em estádios de futebol no estado do Maranhão e se orgulhava em propagandear o nascimento de uma obra que, segundo disse, havia sido recusada em programas de pós-graduação stricto senso para o ingresso no doutorado. A investigação que deu origem ao livro foi feita de modo independente, sem vínculo universitário, o que gerou uma afirmação na introdução do livro de que não apenas nos meios institucionais se produz conhecimento (!).

A obra tem uma estrutura relativamente simples, contendo prefácio e apresentação (de amigos doutorandos do autor), uma introdução, quatro capítulos e uma breve conclusão. Os três primeiros capítulos são longos e fundamentalmente teóricos, enquanto o curto quarto capítulo apresenta a pesquisa conduzida por Moura em estádios do Maranhão (três localidades no interior e na capital São Luiz) e sobre a qual os amigos destacam a relevância de ser "fora do eixo, desprendida dos centros urbanos onde estão os grandes clubes brasileiros".1

Moura está preocupado com o ato de torcer dentro dos estádios de futebol e, mais particularmente, com a figura do "torcedor homossexual", em seus termos. Chama a "livre expressão do torcer" de "exercício cultural" que garante o lugar de privilégio do homem heterossexual no reforço de estereótipos e opressões dentro do espaço futebolístico. 0 problema explicitado na introdução é indagar como o discurso de ódio, por meio da chamada "liberdade de expressão", garante

\footnotetext{
${ }^{1}$ SIMÕES. Apresentação, p. 17.
} 
reprodução coercitiva das "masculinidades", desembocando no disparar de xingamentos homofóbicos nos estádios. Intento louvável, eu diria. A rota escolhida pelo autor, deslindada ao longo dos capítulos, é um apanhado de autores/as das Ciências Sociais e do Direito, especialmente a teoria do discurso de Michel Foucault.

Além disso, Moura ainda aposta na "ordem sociojurídica liberal", que tem influência direta na "liberdade de expressão" no campo de futebol a partir das expressões de homofobia. Como menciona, "a ordem sociojurídica deve ser analisada, neste ponto, sob a ótica de um discurso de liberdade de expressão como um direito". ${ }^{2}$ Este talvez seja o ponto perseguido em todo o livro, visto que ele habita, a todo o tempo, o universo do Direito.

Portanto, sua proposta é perceber como, mesmo dentro de um espaço do lúdico e do esportivo ainda existe uma profusão de discursos, que leva ao futebol a reprodução de falações sobre a masculinidade - que, enunciada nos capítulos 1 e 3 , não aparece conceituada ou mesmo problematizada. Afinal, ao término da leitura fiquei me questionando sobre que masculinidade(s) o autor trata? Existiria uma performance de "masculinidade futebolística nordestina" (termos meus), por exemplo? Ou como se caracterizam as masculinidades dos jogadores de séries inferiores, como parece ser o caso ilustrado no Maranhão?

De qualquer forma, para se construir enquanto homem é preciso diferenciar-se de mulheres e crianças, e ostentar uma masculinidade que os diferencie dele pelo reforço da virilidade e autonomia. 0 "homossexual”, portanto, estaria vinculado às mulheres, pois não teria garantida pelo senso comum a virilidade heterossexual (atributo chave da masculinidade). 0 argumento de Moura, nesse sentido, constrói-se sobre uma masculinidade que é pautada pelo sexismo e pela homofobia (aversão ao igual).

No tocante à homofobia, o autor também não aprofunda o conceito, nem na introdução, nem nos demais capítulos, muito menos na parte em que apresenta sua breve pesquisa em estádios (afinal, o que os/as entrevistados/as compreendiam por tal fenômeno?). Para ele, homofobia se definiria como o "preconceito social produzido por certas invisibilidades de identidades caracterizadas pela sexualidade,

\footnotetext{
${ }^{2}$ MOURA. Jogue como homens, p. 29.
} 
as quais legitimam inferiorizações e deslegitimações sociais por meio da linguagem". ${ }^{3}$ Entretanto, como nos mostrou Daniel Borillo, ${ }^{4}$ homofobia é mais do que isso e não é um conceito fechado, mas sim circunstancializado.

Ademais, para tratar da homofobia enquanto um sistema de perpetuação de impostações contra corpos, gêneros e sexualidades, deve-se levar em conta que ela é mantida por "um sistema de garantia da heterossexualidade normativa e da dicotomia e assimetria de gênero, que funcionam através das estruturas do parentesco e das representações do corpo sexuado e suas atividades". ${ }^{5}$ E, assim, a manutenção da dicotomia entre quem explicita e quem sofre de homofobia se dá por meio de um processo instituído de dessubjetivação, que sujeita alguém não heterossexual às rígidas categorias da heteronormatividade, decompondo-o e o impedindo-o de se pronunciar (particularmente em estádios de futebol).

Algo importante no capítulo 1 diz respeito à noção de virilidade. Para Moura, nos estádios ou na sociedade, não interessa a maior medida de virilidade, mas a aparência dela. Neste ponto importa entender que o autor "cola" virilidade e explicitação de atos (agilidade, violência, força etc.) ao corpo do homem (notadamente, masculino), como se apenas o corpo dos "machos da espécie" pudesse deliberadamente explicitá-la. Aqui, é preciso se lembrar de que a virilidade da ação não é prerrogativa de tais "machos", em que pese Moura estar considerando isso em seu trabalho. Da mesma forma que Halberstam (2008) mostrou que a masculinidade não é exclusividade de corpos de homens (por isso, trata de feminilidades masculinas), haveria que se considerar que mulheres e demais sujeitos sexuais também poderiam evocar a virilidade em seus comportamentos, dentro ou fora dos estádios.

Outro ponto vinculado a este, também importante de ser comentado, é o relativo à figura por ele evocada do "homossexual", o outro que é chamado para ser inserido e, logo em seguida, excluído - ponto de vista encampado, particularmente, no capítulo 3, mas carregado até as últimas páginas do livro. Aqui o autor é sagaz, por um lado, ao conclamar a figura do "homossexual" para exatamente, demonstrar

\footnotetext{
${ }^{3}$ MOURA. Jogue como homens, p. 29.

${ }^{4}$ BORILLO. Homofobia, 2010.

${ }^{5}$ VALE DE ALMEIDA. A chave do armário, p. 14.
} 
que a lógica de afirmação de uma masculinidade/virilidade no futebol necessita de seu contrário e contraponto. 0 sujeito não alinhado à heterossexualidade seria 0 contrário e contraponto do homem heterossexual, "macho em essência" (palavras minhas e aspas irônicas). Um apenas existiria perante (e com) o outro. $\mathrm{O}$ argumento de Moura é que o "homossexual" não apenas aparece no cenário futebolístico de forma clandestina, mas igualmente traficada. A homossexualidade personificada seria o elemento fundamental de controle sobre quem pode ou não estar relacionado ao campo das práticas futebolísticas.

Em que pese ter entendido a referência e os sentidos instituídos pelo autor em relação à homossexualidade, algo que me surpreende é ele não problematizar a categoria (e chamamento) homossexual/homossexualidade como dada, imutável, fixa. Em realidade, o nó da questão nem é o tomar a homossexualidade como uma "identidade fixa", pois, apesar de isso ser reducionista, muitas vezes ela aparece como categoria êmica no campo de investigação (por exemplo, nos discursos de seus interlocutores em torcidas maranhenses). A questão seria problematizar tal fato.

De outra parte, poderia ter-se perguntado: quem disse que "homossexuais" não são masculinos? Ou quem disse que não existem "homossexualidades viris"? Muitos homens que têm relações afetivo-sexuais com outros homens estão no universo do futebol, identificam-se com a estética dominante de uma "masculinidade hegemônica" (por assim dizer) e se recusam a habitar o "armário da sexualidade". ${ }^{6} \mathrm{Se}$, como afirma Moura, os valores masculinos também são "fluídos, transitórios e incompletos", 7 por que não poderiam estar à disposição de corpos considerados (ou enunciados) como "homossexuais"? Considero problemática a afirmação: "Em que pesem as discursividades sobre evitar os preconceitos, o sujeito homossexual ainda persiste em um não lugar. Não é masculino, ao mesmo tempo em que não é feminino". 8

Ainda no capítulo 3, não obstante fazer ressalvas sobre a existência de políticas públicas que emergem para garantir direitos de participação esportiva a pessoas identificadas com as homossexualidades (?), o autor é descrente em relação

\footnotetext{
${ }^{6}$ CAMARGO. O armário da sexualidade no mundo esportivo, 2018a.

${ }^{7}$ MOURA. Joguem como homens, p. 63.

${ }^{8}$ MOURA. Joguem como homens, p. 90.
} 
a elas, dizendo que tais pessoas sofrem um "perigo" iminente de exclusão. Isso porque "à medida que surgem os discursos contra enunciados homofóbicos, ao mesmo tempo reage-se a esses discursos com práticas cada vez mais homofóbicas". ${ }^{9}$ E menciona que, nem iniciativas como a dos Gay Games, que apresentam "força política de extrema relevância" na sociedade, ${ }^{10}$ conseguem reverter o lugar de inferioridade atrelado à homossexualidade.

Um megaevento multiesportivo como o Gay Games, por exemplo, que envolve uma quantidade de milhares de pessoas desloca, ${ }^{11}$ segundo Moura, o lugar do "sujeito criado para ser odiado" dentro do esporte, seja porque a heterossexualidade é estética minoritária ou inexistente, seja porque há uma implosão nos polos superioridade/inferioridade a partir dos corpos sexualizados e generificados. Poder-se-ia dizer, portanto, que haveria aí um impeditivo inexorável de subversão das lógicas instituídas nestes espaços esportivos, ocupados por sujeitos não alinhados à heteronormatividade, negando a possibilidade de novas articulações nos discursos e mesmo da rearticulação do poder. ${ }^{12}$

No capítulo 4, quando o fim do livro já está praticamente anunciado, o autor apresenta sua "pesquisa de campo" (segundo ele, algo raro na área do Direito) e a coleta realizada em estádios de futebol do estado do Maranhão. Apesar de não informar a amostragem e nem como a parte quantitativa foi planejada, relatou que foram 102 entrevistados (88 homens e 14 mulheres), em cinco estádios da capital São Luiz e mais quatro do interior. Mencionou também que foram analisados "outros espaços" (como bares e residências), nos quais os sujeitos puderam "refletir" sobre futebol - porém, não conferiu mais detalhes de tais afirmações.

Algo que fiquei me questionando ao ler seu relatório sobre a "pesquisa de campo" foi o fato de não terem sido apresentadas opiniões destes/as entrevistados/as

\footnotetext{
${ }^{9}$ MOURA. Joguem como homens, p. 114.

${ }^{10}$ MOURA. Joguem como homens, p. 115.

${ }^{11}$ CAMARGO. Jogos 'Olímpicos' Gays, 2018b.

12 Penso que, mediante a trajetória de estudos que tenho desenvolvido sobre os Gay Games, apenas em publicações na língua portuguesa, Moura poderia ter executado uma pesquisa bibliográfica para ter mais elementos a considerar sobre esta afirmação tão problemática (CAMARGO. Circulando entre práticas esportivas e sexuais, 2012; CAMARGO. Uma história diferente, 2014; CAMARGO, Esporte, cultura e política, 2016; CAMARGO, Jogos 'Olímpicos’ Gays, 2018b).
} 
sobre o que consideravam "liberdade de expressão", mote central do livro e da delimitação bibliográfica dos capítulos anteriores. Além disso, uma importante questão levantada por Moura, qual seja, "o que sobra quando existe limite à liberdade de expressão?",13 não é respondida ou aprofundada no decorrer final dos escritos.

Um último comentário é acerca da reprodução acrítica de estereótipos promovida pelo autor, quando menciona as torcidas organizadas como locais de "promoção de atos violentos": "A título de informação, apenas 10\% dos entrevistados afirmaram pertencer a grupos de torcidas organizadas - resultado expressivo, dada a condição marginal desses grupos no que se refere ao espaço do futebol, pois são considerados grupos que existem para promoção de atos violentos". ${ }^{14}$ Aqui, Moura demonstra que desconhece a produção sobre torcidas organizadas ${ }^{15}$ e mesmo sobre as múltiplas dimensões da violência propagada por tais agrupamentos. ${ }^{16}$ Independentemente de reconhecer que a "violência não é apenas física, mas pode ser simbólica, como nos cânticos dos torcedores organizados",17 estabelece um equívoco ao não endereçar que os efeitos simbólicos dos discursos preconceituosos e discriminatórios não são emitidos apenas por torcedores, mas sim a partir de outros agentes no futebol, como os especialistas e os jogadores. ${ }^{18}$

O que o autor chama de "método dialético"19 para a apresentação do estudo, eu chamaria de "confuso". Com capítulos que anunciam temáticas que não se aprofundam, conceitos pouco ou nada desenvolvidos (homofobia, masculinidade, virilidade, homossexualidade) e uma investigação mal apresentada (sem explicação metodológica condizente), o livro atordoa leitores/as acadêmicos/as pelo excesso de citações, diretas ou indiretas (muitas vezes desnecessárias) e os deixa confusos/as quanto ao que, de fato, foi o propósito da obra. Para um público mais geral, excetuando-se o título, o conteúdo do livro é inacessível, seja pelo linguajar conceitual muito hermético do Direito e pelos jargões das Ciências Sociais, seja pela não aproximação com as situações cotidianas vividas nos estádios (por quem

\footnotetext{
${ }^{13}$ MOURA. Joguem como homens, p. 126.

${ }^{14}$ MOURA. Joguem como homens, p. 121-122 (grifos meus).

15 TOLEDO. Torcidas organizadas de futebol, 1996. TOLEDO. Lógicas no futebol, 2002.

${ }^{16}$ REIS. Violência e futebol, 2006.

${ }^{17}$ MOURA. Joguem como homens, p. 48.

18 TOLEDO. Lógicas no futebol, 2002.

${ }^{19}$ MOURA. Joguem como homens, p. 26.
} 
desfere os xingamentos ou por quem são seus alvos). Para mim, o grande enigma a ser decifrado é saber para quem Moura escreveu este livro.

Por fim, em tempos tão catastróficos como os que vivemos na era Bolsonaro, a orgulhosa afirmação de que o conhecimento também é produzido extramuros acadêmicos pode ser uma perigosa alegação de que a universidade é dispensável e já não presta ao propósito a que foi criada. Moura pode até ter publicado seu livro à revelia dos procedimentos convencionais (em que pese o volumoso quadro de pareceristas do conselho editorial, apresentados nas páginas iniciais). Porém, a qualidade de sua pesquisa não foi colocada sob avaliação por pares (das Ciências Sociais ou do Direito), procedimento comum e necessário para a validação formal de conhecimento. Portanto, o livro aqui apresentado deve ser tomado com muita cautela.

\section{REFERÊNCIAS}

BORILLO, Daniel. Homofobia: história e crítica de um conceito. Trad. Guilherme J. F. Teixeira. Belo Horizonte: Autêntica, 2010.

CAMARGO, Wagner Xavier. O armário da sexualidade no mundo esportivo. Revista Estudos Feministas, v. 26, p. 1-18, 2018a.

CAMARGO, Wagner Xavier. Jogos 'Olímpicos' Gays: uma perspectiva antropológica. In: Sérgio S. Giglio; Silvia Cristina F. Amaral; Olívia Cristina F. Ribeiro; Marco Antonio C. Bortoleto (Org.). Múltiplos olhares sobre os Jogos Olímpicos. São Paulo: Intermeios, v. 1, p. 177-201, $2018 \mathrm{~b}$.

CAMARGO, Wagner Xavier. Esporte, cultura e política: a trajetória dos Gay Games nas práticas esportivas contemporâneas. Revista USP, v. 1, p. 97-114, 2016.

CAMARGO, Wagner Xavier. Uma história diferente: os Gay (Olympic) Games e sua origem. Revista Homium, v. 1, p. 36-54, 2014.

CAMARGO, Wagner Xavier. Circulando entre práticas esportivas e sexuais: uma etnografia em competições esportivas internacionais LGBTs. Tese (Doutorado em Ciências Humanas). Universidade Federal de Santa Catarina, Florianópolis, 2012. 
HALBERSTAM, Judith Jack. Masculinidad femenina. Madrid-Barcelona: Egales, 2008.

MOURA, João Carlos da Cunha. Joguem como homens! Masculinidades, liberdade de expressão e homofobia em estádios de futebol no estado do Maranhão. Jundiaí: Paco Editorial, 2019. 152 p.

REIS, Heloísa Baldy. Violência e futebol. São Paulo: FAPESP, 2006.

SIMÕES, Irlan. Apresentação. In: MOURA, João Carlos da Cunha. Joguem como homens! Masculinidades, liberdade de expressão e homofobia em estádios de futebol no estado do Maranhão. Jundiaí: Paco Editorial, 2019, p. 13-20.

TOLEDO, Luiz Henrique. Lógicas no futebol. São Paulo: Hucitec/Fapesp, 2002.

TOLEDO, Luiz Henrique. Torcidas Organizadas de futebol. Campinas: Autores Associados/ANPOCS, 1996.

VALE DE ALMEIDA, Miguel. A chave do armário: homossexualidade, casamento, família. Lisboa: Imprensa de Ciências Sociais, 2009. 